Institute of $\mathbf{F}_{\text {ood and }} \mathbf{A g r i c u l t u r a l}_{\mathbf{S}}$ ciences

\title{
Florida LAKEWATCH and Aquatic Bird Surveys: A Winning Combination ${ }^{1}$
}

\author{
Ashley H. Traut, Mark E. Hostetler, Eric J. Schulz, and Mark V. Hoyer ${ }^{2}$
}

Do you spend time on Florida lakes? Do you enjoy watching birds? Would you like to contribute to the understanding of birds on Florida lakes? If you answered "yes" to any of these questions, then Florida LAKEWATCH wants YOU!

\section{What is Florida LAKEWATCH?}

Florida LAKEWATCH is a statewide lake-monitoring program conducted by volunteer citizens. It gives citizens an opportunity for "hands-on" participation in the management of Florida lakes through monthly water-sampling activities. Citizen volunteers help biologists achieve a better understanding of these lake systems than the biologists could ever achieve alone.

Florida LAKEWATCH is coordinated through the University of Florida's Institute of Food and Agricultural Science's (UF/IFAS) Department of Fisheries and Aquatic Sciences. The program has been in existence since 1986. In 1991, the Florida Legislature recognized the importance of the program and established Florida LAKEWATCH in the state statutes (Chapter 91-69; s240.5329, F.S.).

Florida LAKEWATCH is now one of the largest lake-monitoring programs in the nation. It has historical data on more than 1,200 lakes in Florida. Currently, more than 1,800 trained citizen volunteers are monitoring over 600 lakes. Out of 67 counties in Florida, more than 50 counties $(75 \%)$ have lakes that are being monitored by Florida LAKEWATCH volunteers.

\section{Adding Aquatic Bird Surveys to Florida LAKEWATCH}

Since the beginning of Florida LAKEWATCH, there has been a desire to record the types of birds that use Florida lakes. Many bird species are known to use lakes, but few studies have recorded how many or examined long-term trends in diversity. For Florida LAKEWATCH's purposes, "aquatic birds" are defined as "all bird species that use any type of aquatic or shoreline habitat on Florida lakes."

1. This document is Fact Sheet WEC _ , one of a series of the Department of Wildlife Ecology and Conservation, Florida Cooperative Extension Service, Institute of Food and Agricultural Sciences, University of Florida. First published in October 2002. Please visit UF's EDIS Web site at http://edis.ifas.ufl.edu for more publications.

2. Ashley H. Traut, Graduate Student, Dept. of Wildlife Ecology and Conservation; Mark E. Hostetler, Assistant Professor and Extension Wildlife Specialist, Dept. of Wildlife Ecology and Conservation; Eric J. Schulz, Florida LAKEWATCH Regional Coordinator, Dept. of Fisheries and Aquatic Sciences; Mark V. Hoyer, Scientific Research Manager, Dept. of Fisheries and Aquatic Sciences; Florida Cooperative Extension Service, Institute of Food and Agricultural Sciences, University of Florida, Gainesville, FL 32611

The use of trade names in this publication is solely for the purpose of providing specific information. UF/IFAS does not guarantee or warranty the products named, and references to them in this publication does not signify our approval to the exclusion of other products of suitable composition.

The Institute of Food and Agricultural Sciences is an equal opportunity/affirmative action employer authorized to provide research, educational information and other services only to individuals and institutions that function without regard to race, color, sex, age, handicap, or national origin. For information on obtaining other extension publications, contact your county Cooperative Extension Service office. Florida Cooperative Extension Service/Institute of Food and Agricultural Sciences/University of Florida/Christine Taylor Waddill, Dean. 
As Florida's wetlands continue to be altered or destroyed, lakes are becoming more important. We need to document which birds use lakes, and monitor the distribution and abundance of birds on or around Florida lakes. This will help us develop future management strategies for preserving lake habitat.

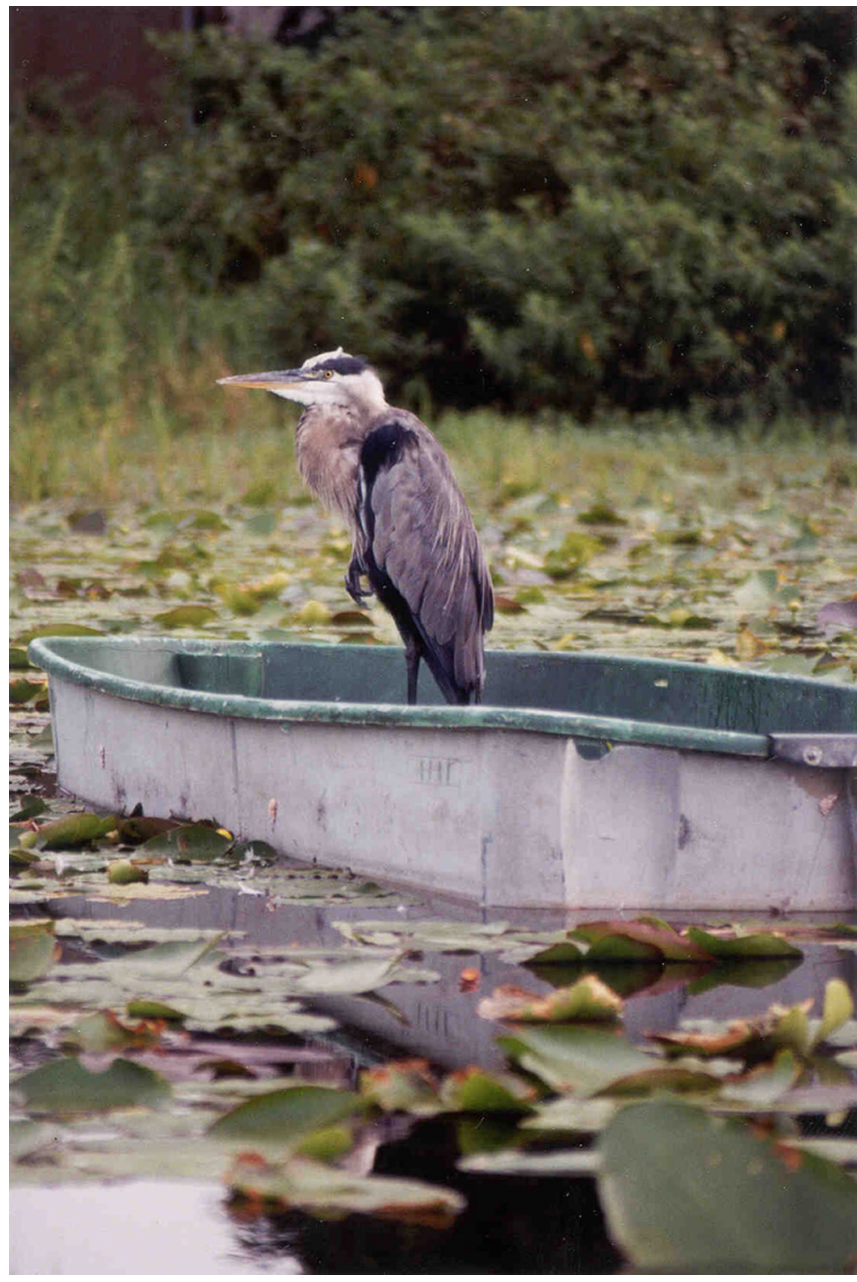

Figure 1. One of the wading birds commonly seen on Florida lakes -- the Great Blue Heron. Photo by Ashley Traut.

\section{Objective of Florida LAKEWATCH Bird Surveys}

The objective of the Florida LAKEWATCH Aquatic Bird Survey is to establish a standardized, statewide program for monitoring birds on Florida lakes through surveys conducted by volunteers. These surveys (or "counts") will help biologists examine seasonal and yearly trends in populations of birds that use lakes. The information gathered will offer insights into the effects of shoreline habitat, lake-water chemistry, and broad-scale climatic factors on the feeding, nesting, and roosting of aquatic birds.

\section{The Value of Volunteers}

The value of volunteer participation cannot be stressed enough. It is the essence of the Florida LAKEWATCH water-sampling program. With the data they gather, citizen volunteers are helping biologists understand and monitor Florida lake systems. Usually, biologists only have time to visit a lake only once or twice a year. So, they could never achieve the same level of understanding without volunteer assistance.

\section{The Call for Volunteers}

As with lake monitoring, volunteer assistance is the most practical way to efficiently gather data on birds that use Florida lakes. Over the long-term, such volunteer monitoring efforts help biologists detect changes in the types and numbers of birds using Florida lakes. Such changes in bird populations could indicate a response to natural or human-caused environmental factors. If birds are responding to an environmental factor, how widespread is this response? Which Florida lakes are exhibiting this change in bird populations and are these lakes clumped in a certain region or found randomly all over the state?

Volunteers who conduct monthly bird surveys statewide are incredibly valuable to biologists and to the sound management of lakes in Florida.

\section{Successful Volunteer Bird-Monitoring Programs}

Volunteer bird-monitoring programs are by no means a new idea. There are many successful state and national programs. These include the Christmas Bird Count (CBC) and the Breeding Bird Survey (BBS).

The Christmas Bird Count (CBC) was started in 1900 in response to the excessive hunting of birds. It now has roughly 45,000 participants throughout North and South America. Conducted annually near Christmas, the $\mathrm{CBC}$ is "the "oldest and largest wildlife survey in the world." 
The Breeding Bird Survey (BBS) is also a large-scale, volunteer survey of North American birds. The BBS was started in 1966 as a roadside survey and currently has more than 3,500 routes across the U.S. and southern Canada. Experienced birders survey birds from the roadside on these routes every June.

In Florida, a study conducted by Florida LAKEWATCH volunteers and coordinators has demonstrated that volunteers can provide valuable information on the long-term status of Florida's aquatic bird populations. The study results were published in the Journal of Lake and Reservoir Management 17:1-8.

\section{Are You Interested?}

If you want to conduct bird surveys for Florida LAKEWATCH, send an email message expressing your interest to Eric Schulz, Florida LAKEWATCH Regional Coordinator, at lakewat@ufl.edu. Send him your name, mailing address, zip code, phone number, email address, the name of the lake you want to survey, and the county you live in.

Eric will check if your lake's water quality is currently being monitored by Florida LAKEWATCH volunteers or if it was monitored in the past. Either way, he will contact you to discuss your survey plan. If your lake is new to the Florida LAKEWATCH monitoring program, you will need to find someone to do the monthly water-quality sampling. Or, you may choose to do both the bird surveys and the lake-water sampling. You can talk to Eric Schulz about this when he contacts you.

\section{Conducting a Bird Survey for Florida LAKEWATCH}

This program is designed to monitor monthly trends in aquatic bird numbers. We are asking for a commitment of one bird survey per month.

However, if your schedule does not allow for such a commitment, surveying every other month or even quarterly would still provide useful data. Of course, surveys can be done as often as once a week. Bird surveys can be done either in conjunction with water sampling or on a separate day.

\section{Learn the Birds in Your Area}

Before you begin actual bird counts (surveys), please learn which birds frequent your lake and shoreline. Using a field identification guide, learn to identify all of the birds on the Field Data Sheet. Two very good field guides for identifying birds are: Roger Tory Peterson's A Field Guide to the Birds of Eastern and Central North America (Fourth or Fifth Edition) and the National Geographic Guide to Birds of North America (Second or Third Edition). However, there are certainly many excellent guides to choose from at your local bookstore.

\section{Follow This Method for Bird Surveys}

Numerous methods have been developed to survey birds. Each method has its advantages and disadvantages. For the purposes of this project, bird counts should be conducted by boating slowly once around the edge of your lake and counting all aquatic birds that you observe.

One way that your data will be used is in comparing your lake with other lakes in Florida. To prevent inaccurate (biased) data results, it is important that every volunteer survey birds in the same method.

\section{Survey from Boat or Shore}

Although we prefer that surveys be done from a boat, we will accept standardized surveys performed from the shore. Just make sure to note on your Data Sheet that the surveys were done by walking around the lake's shore (transect method) or were conducted from a fixed location such as a dock or yard (point count method). If you would like to survey birds in a different way than described, please contact Florida LAKEWATCH (phone: 1-800-525-3928, Email: lakewat@ufl.edu).

\section{Best Time of Day}

Ideally, the primary monthly survey should be conducted between sunrise and 12:00 noon. However, you can do the surveys at other times. Just remember to record both the start and finish times of your survey. If you want to conduct more than one survey per month, try to include evening counts to help detect roosting sites. Evening surveys should be done 
as close to sunset as possible, but no earlier than 1.5 hours before sunset (e.g., if the sun sets at 7 p.m., start surveying no earlier than 5:30 p.m.). Make sure to allow enough daylight to complete the entire survey.

\section{Team Effort vs. Solo}

It is best if two people can do a bird survey together. With one person driving the boat, the other person can then devote his/her full attention to counting birds. This method will usually result in more accurate data than when one person tries to drive and count birds at the same time. But if you have to do the survey alone, that is still acceptable. Just be careful. Take your time so you don't run into a dock, stump, or another boat while you are busy counting birds!

\section{Weather}

For your safety and enjoyment, bird surveys should be done on days with no rain and low winds. Also, birds are active and more visible during good weather. At the beginning of each count you should record general weather conditions. Include wind intensity, temperature, an estimate of percent cloud coverage, and any other observations that may be significant (see Field Data Sheet in Table 1).

\section{Boating Speed}

You should travel at a slow, steady, no-wake speed during the survey. For your first few surveys, try to travel at slower speeds. This allows you to get an accurate bird count. As you become more familiar with the birds and all their hiding places, you can slightly increase your speed. Try to stay close to the lake's shore, as close as the aquatic vegetation and water depth will allow. This is especially important around areas of emergent aquatic vegetation, such as cattails, where aquatic birds may hide.

\section{Counting and Recording Birds}

The Field Data Sheet (see Table 1) lists birds most commonly seen on Florida lakes. The Data Sheet list is not all-inclusive, so if you see a bird species that is not listed there, please refer to a field guide and write the species in the "Notes" section of the Data Sheet. Florida LAKEWATCH bird surveys are for monitoring "aquatic" birds only, but you may want to record other birds for your own interest (on back of Data Sheet or separate paper). For Florida LAKEWATCH's purposes, "aquatic birds" are defined as "all bird species that use any type of aquatic or shoreline habitat on Florida lakes."

Be alert for uncommon or rare species. If you see a species that is not listed on the Field Data Sheet (Table 1) then please record the species name and number of birds in the "Notes" box on the Data Sheet. You can also use the back of the Data Sheet if you need more room. Just make a note to see the back for additional data.

It is important to avoid counting the same bird more than once. Often birds will flush from their position when disturbed. Should they fly ahead of you and land along a portion of the shoreline that you have not yet surveyed, make a mental note of their new location. Do not count them when you pass them a second time. If large flocks of birds are encountered, it can be very difficult to get an accurate count. Do not try to count each individual bird. Rather, try counting a group of 10 or 20 and then estimate how many groups of that size you see. This will take practice but will ultimately make your job much easier.

Try to identify all aquatic birds to the species level. In other words, if you see a heron, try to figure out which kind (species) of heron it is...but don't guess. If the lighting is bad or you got only a brief look and can't be sure of the species, then record it as "unidentified" in the Notes section of the Data Sheet. Note the closest bird type that you can determine (for example, "unidentified heron" or "unidentified duck"). This type of data is still important! It can be used to study which types of birds are found in the area.

\section{Exceptions}

Some species that are related to each other are difficult to tell apart. They are separate species, but they also belong to a larger group -- a taxonomic Family. These difficult-to-distinguish species include rails, plovers, sandpipers, gulls, terns, swifts, swallows, and crows. For Florida LAKEWATCH 
surveys, record these types of birds in the above groupings (see Field Data Sheet, Table 1).

\section{Practice Your Survey Route}

Before starting official surveys, you may find it helpful to practice boating your route. This will help you become familiar with the habitat and birds on your lake. Practicing your survey will sharpen your observation skills and make it easier to record birds quickly on the Field Data Sheet (see Table 1) during official surveys.

If you have any questions, at any time, please feel free to contact Eric Schulz, Florida LAKEWATCH Regional Coordinator, at lakewat@ufl.edu or at 1-800-525-3928. Florida LAKEWATCH coordinators and volunteers are always glad to help!

\section{Enter Bird Survey Data Online}

You will always send your Field Data Sheets to Florida LAKEWATCH for their records, however you can also enter your data online for your personal record! This is a unique opportunity to keep your bird survey data organized online for your personal enjoyment and also to share your survey data with people throughout Florida, the nation, and the world.

If you're interested in entering your Florida LAKEWATCH bird survey data online, you can go to the Web site for the Florida Bird Monitoring Program (http://bird.ifas.ufl.edu) developed by UF's Department of Wildlife Ecology and Conservation's Extension office. With your data saved on this Web site, you can track over time the bird species that you have been seeing on your lake. For example, you could compare the data you collected during different seasons or years, or during periods of high human activity versus periods of low human activity on the lake. If you conduct morning and evening bird surveys, you could compare those records as well.

On this Web site, you can also view bird survey data for other Florida LAKEWATCH lakes (if other bird surveyors are recording their data on this Web site). You can even search for specific species to see if it is being seen at other LAKEWATCH lakes that have data entered on this Web site! For more information, please visit the Florida Bird Monitoring Program Web site at http://bird.ifas.ufl.edu.

\section{References}

Butcher, G. S. 1990. Audubon Christmas Bird Counts. In J. R. Sauer and S. Droege, Eds. Survey designs and statistical methods for the estimation of avian population trends (pp. 5-13). U.S. Fish Wildl. Serv. Biol. Rep. 90(1).

Sauer, J. R., J. E. Hines, I. Thomas, J. Fallon, and G. Gough. 2000. The North American Breeding Bird Survey, Results and Analysis 1966 - 1999. Version 98.1. Available on Web site of USGS Patuxent Wildlife Research Center, Laurel, MD: http://www.pwrc.usgs.gov

Hoyer, M. V., J. Winn, and D. E. Canfield Jr. 2001. Citizen monitoring of aquatic bird populations using a Florida lake. Lake and Reservoir Management 17:1-8. 


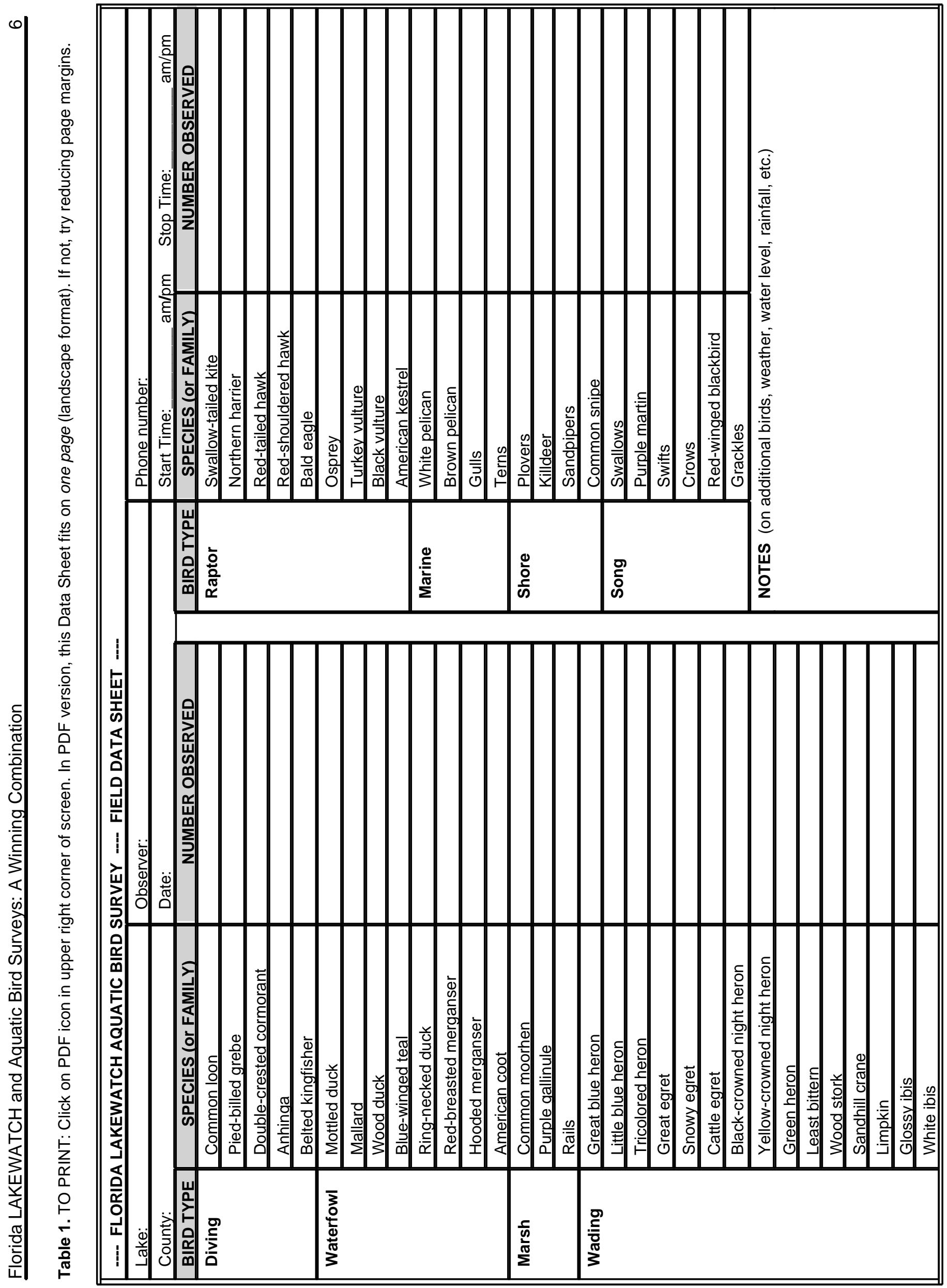

